\title{
Method Development, Validation and Stability Indicating Studies of Rifabutin Using HPLC-DAD
}

\section{Seema B Kharwade ${ }^{1 *}$, Narendra G Patre ${ }^{1}$, Sunil S Talde ${ }^{2}$, Asmita S Tupe $^{3}$, Ajay D Kshirsagar ${ }^{1}$, Sudam G Mule ${ }^{1}$}

${ }^{1}$ DK Patil Institute Of Pharmacy, MH, India

${ }^{2}$ Vivekvardhini Sevabhavi Sanstha's College Of Pharmacy, MH, India

${ }^{3}$ Prerna Institute Of Pharmacy, $\mathrm{MH}$, India

*Corresponding Author: Seema B. Kharwade DK, Patil Institute Of Pharmacy, MH, India.
Received: August 20, 2021

Published: October 04, 2021

(C) All rights are reserved by Seema

B Kharwade., et al.

\begin{abstract}
Introduction: Pharmaceutical analysis involves separating, identifying and determining relative amounts of the compounds in give formulation. It comprises of those procedures which are necessary to determine the identity, strength, quality and purity of drugs and chemicals. These are classified into non-instrumental and instrumental methods like spectroscopy, chromatography, electrochemical etc.

Aim and Objectives: To develop HPLC-DAD method for the Rifabutin in bulk and capsule dosage form, to validate the developed methods and stability indicating studies as per ICH guidelines.

Method: A Shimadzu SCL-10AVP; Quaternary Pump using C-18 column Zodiac-100 with dimensions of 150 x $4.6 \mathrm{~mm}$ and silica particle size of $5 \mu \mathrm{m}$. Analyte Concentration of 250 - 15.62 ppm was used. Isocratic elution employed with A; 0.5\% Trifluoroacetic Acid, B; Acetonitrile (30:70 v/v) were used. Flow rate was $1.2 \mathrm{ml} / \mathrm{min}$ and effluents were monitored at 275 and $310 \mathrm{~nm}$ wavelength at $28^{\circ} \mathrm{C}$. HPLC method was extensively validated for precision, robustness and stability indicating studies.

Result: Wavelength of maximum absorbance ( $\lambda$ max) of Rifabutin was $275 \mathrm{~nm}$ and 310nm and was identical for both marketed preparation and API. Correlation coefficient was found to be 0.999 . Interday and intraday precision was 1.93 and 0.89 respectively. The stability indicating studies or force degradation studies were also performed for Rifabutin drug. As concluded, drug was seen stable in thermal, oxidation and acid induced hydrolysis.

Conclusion: It can be concluded that the developed methods are accurate, precise and selective and can be employed successfully for the estimation of Rifabutin in bulk and capsule dosage form.
\end{abstract}

Keywords: Rifabutin; HPLC-DAD and $\lambda$ Max

\section{Abbreviation}

DAD: Diode Array Detector.

\section{Introduction}

Rifabutin is an antibiotic that inhibits DNA-dependent RNA polymerase activity in susceptible cells [1]. It interacts with bacte- rial RNA polymerase but does not inhibit the mammalian enzyme. It is bactericidal and has a very broad spectrum of activity against most gram-positive and gram-negative organisms (including Pseudomonas aeruginosa) and specifically Mycobacterium tuberculosis. It is indicated for the prevention of disseminated Mycobacterium avium complex (MAC) disease in patients with advanced HIV infec- 
tion who concurrently receive protease inhibitors because rifabutin is a less potent inducer of cytochrome P3A than rifampin [2-5].

It showed greater activity than rifampin in M. tuberculosis infections and also active against more than $35 \%$ of strains that are resistant to rifampin $[6,7]$.

Rifabutin is well absorbed when taken orally and is distributed widely in body tissues and fluids, including the CSF and has high intracellular penetration [8]. It is metabolized in the liver and eliminated in bile and, to a much lesser extent, in urine, but dose adjustments are unnecessary with renal insufficiency [9].

Pharmaceutical analysis involves separating, identifying and determining relative amounts of the compounds in give formulation. It comprises of those procedures which are necessary to determine the identity, strength, quality and purity of drugs and chemicals. These are classified into non-instrumental and instrumental [10] methods like spectroscopy, chromatography, electrochemical etc. $[11,12]$.

Pharmaceutical analysis has two branches - Qualitative analysis which deals with identification of atomic or molecular species or the functional groups present in the sample. And quantitative analysis which deals with the determination of how much amount of one or more constituents are present in the sample [13].

The term Chromatography (Greek: Khromatos - color and Graphos - written) means, "colour writing". The beginning of Chromatography started with the work of botanist Micheal Tswett in the year 1896. The term chromatography and its principles were first discovered in 1903 by Micheal Tswett [14]. This technique is based on the separation of components in a mixture (the solute) due to the difference in migration rates of the components through a stationary phase by a gaseous or liquid mobile phase. In all chromatographic separations the sample is transported in a mobile phase and then forced through an immiscible stationary phase, which is fixed in place in a column or on solid surface [15].

\section{Materials and Methods}

\section{Method}

Pure sample of Rifabutin was received as a gift sample from $\mathrm{Au}$ riga Research Pvt. Ltd. Banglore. The percentage purity of Rifabutin was $100.58 \%$ w/w. Formulation containing Rifabutin 150 mg
(Ributine Capsule 150 mg, Lupin Pharmaceuticals, Aurangabad, Maharashtra) was used for the analysis spectroscopy grade Hydrochloric acid and Distilled water were used for UV method. HPLC grade trifluoroacetic Acid and acetonitrile used for HPLC method $[16,17]$.

\section{Instruments}

- UV Spectrophotometer

- HPLC

- $\mathrm{pH}$ meter

- Balance

- Ultrasonicator

\section{Mobile phase}

The mobile phase for chromatography consisted of $0.5 \%$ Trifluoroacetic Acid and Acetonitrile (30:70 v/v).

\section{Validation characteristics}

- Analytical Procedure

- Precision

- Robustness

- Stability indicating studies of Rifabutin or Forced decomposition studies [3]

\section{Sample preparation of rifabutin [11]}

Standard stock solution of Rifabutin was prepared by dissolving $10 \mathrm{mg}$ of drug in $0.5 \mathrm{ml}$ of $0.1 \mathrm{~N} \mathrm{HCl}$ and upto $10 \mathrm{ml}$ of Distilled water to get standard stock solution of $1000 \mu \mathrm{g} / \mathrm{ml}$ by sonicating for $15 \mathrm{~min}$. and further dilutions were made by using distilled water. Samples were diluted to a concentration of 10, 20, 30, 40 and $50 \mu \mathrm{g} / \mathrm{ml}$ and used for method development and validation study.

\section{Chromatographic conditions}

Chromatographic separation was attained using a C-18 column (Zodiac-100; 150 × $4.6 \mathrm{~mm}$. ID. $5 \mu$ particle size). Isocratic elution was employed with Trifluoroacetic Acid and acetonitrile.

\section{Results and Discussion \\ Method development $[18,19]$}

HPLC system was used for the analysis. A HPLC method has been developed and validated for estimation of Rifabutin in bulk 
and capsule dosage form. Cosmosil C-18 (Zodiac-100; 150 × 4.6 $\mathrm{mm}$. ID. $5 \mu$ particle size) column was used as stationary phase. After trying several permutation and combinations, it was found that mixture of $0.5 \%$ Trifluoroacetic Acid and Acetonitrile (30:70 v/v) gives good resolution of peaks with acceptable peak symmetry, as compared to other mobile phases. Flow rate selected was $1.2 \mathrm{ml} /$ minute. Solutions of Rifabutin in appropriate dilution was scanned using Photodiode Array detector (DAD) in the spectrum mode between the wavelength range of $400 \mathrm{~nm}$ to $200 \mathrm{~nm}$ and their spectra was overlaid. The wavelength selected was 275 and $310 \mathrm{~nm}$ wavelength was found to have significant absorbance at this wavelength. The retention time for Rifabutin was found to be $1.2 \mathrm{~min}$.

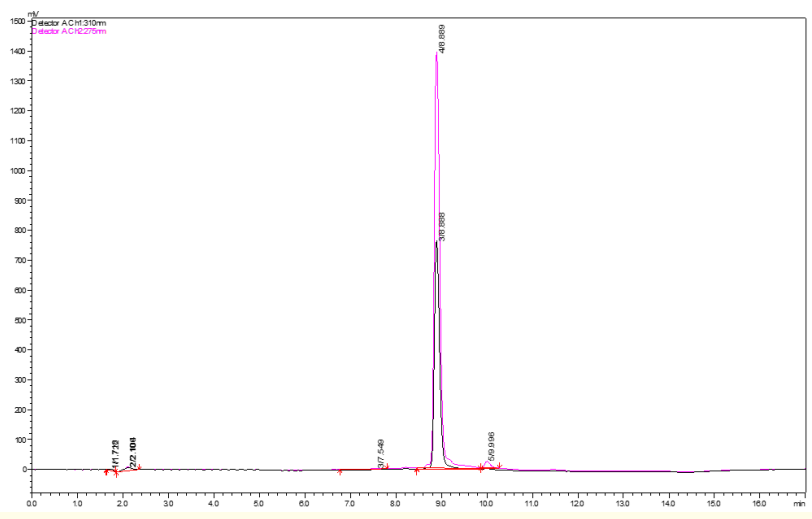

Figure 1: Chromatogram of Rifabutin of $0.5 \%$ Trifluoroacetic Acid and Acetonitrile (30:70 v/v).

\section{Precision [20,21]}

Precision of Rifabutin, the method was verified by repeatability and intermediate precision studies. The precision of the instrument was checked by repeated scanning and measurement of the absorbance's of solutions ( $\mathrm{n}=3$ ) of Rifabutin $30 \mu \mathrm{g} / \mathrm{ml}$ without changing the parameters of the proposed methods. The intraday and interday precisions of the proposed methods were determined by estimating the corresponding responses 3 times on the same day and on 3 different days. The proposed method was found to be precise as indicated by percent RSD of Interday and Intraday was $0.36-1.93$ and $0.36-0.89$ respectively and results were shown in table 1 and 2 .

\begin{tabular}{|c|c|c|c|c|}
\hline S. No. & $\begin{array}{c}\text { Conc. ( } \mu \text { g. } \\
\text { mL-1) }\end{array}$ & Area & Mean \pm SD & \%RSD \\
\hline \multirow{3}{*}{1} & 250 PPM & 6616642 & \multirow{3}{*}{23972.00236} & \multirow{3}{*}{0.36} \\
\hline & 250 PPM & 6583252 & & \\
\hline & 250 PPM & 6570151 & & \\
\hline \multirow{3}{*}{2} & $250 \mathrm{PPM}$ & 6602481 & \multirow{3}{*}{130140.8011} & \multirow{3}{*}{1.93} \\
\hline & $250 \mathrm{PPM}$ & 6810784 & & \\
\hline & $250 \mathrm{PPM}$ & 6841789 & & \\
\hline \multirow{3}{*}{3} & 250 PPM & 6576773 & \multirow{3}{*}{77941.83736} & \multirow{3}{*}{1.18} \\
\hline & 250 PPM & 6661674 & & \\
\hline & 250 PPM & 6506004 & & \\
\hline \multicolumn{4}{|c|}{ Average of RSD (\%) } & $0.36-1.93$ \\
\hline
\end{tabular}

Table 1: Intraday Precision Study.

\begin{tabular}{|c|c|c|c|c|}
\hline $\begin{array}{l}\text { S. } \\
\text { No. }\end{array}$ & Conc. ( $\mu$ g.mL-1) & Area & Mean \pm SD & \%RSD \\
\hline \multirow{3}{*}{1} & 250 PPM & 6616642 & \multirow{3}{*}{23972.0024} & \multirow{3}{*}{0.36} \\
\hline & 250 PPM & 6583252 & & \\
\hline & 250 PPM & 6570151 & & \\
\hline \multirow{3}{*}{2} & 250 PPM & 6724541 & \multirow{3}{*}{60753.9554} & \multirow{3}{*}{0.89} \\
\hline & 250 PPM & 6810784 & & \\
\hline & 250 PPM & 6841789 & & \\
\hline \multirow{3}{*}{3} & 250 PPM & 6576773 & \multirow{3}{*}{42630.9232} & \multirow{3}{*}{0.65} \\
\hline & 250 PPM & 6582571 & & \\
\hline & 250 PPM & 6506004 & & \\
\hline \multicolumn{4}{|c|}{ Average of RSD (\%) } & $0.36-0.89$ \\
\hline
\end{tabular}

Table 2: Interday Precision Study.

\section{Robustness of rifabutin}

Each factor selected to examine were changed at three levels. One factor at the time was changed to estimate the effect. Insignificant differences in peak areas and less variability in retention time were observed. The proposed method was found to be precise as indicated by SD of Rifabutin. Results were shown in table 3 and figure $2,3,4$ and 5 .

The robustness of Rifabutin, the method was judged by deliberately altering the mobile phase composition by $\pm 5 \% \mathrm{v} / \mathrm{v}$ (i.e., $0.5 \%$ 


\begin{tabular}{|l|c|c|c|c|}
\hline Variables & $\mathbf{t}_{\mathbf{R}}$ (min) & $\mathbf{k}^{\prime}$ & $\mathbf{T f}$ & $\mathbf{N}$ \\
\hline $\begin{array}{l}\text { Flow rate (+0.2 } \\
\text { mL.min-1) }\end{array}$ & 8.39 & 3.63 & 1.33 & 30586 \\
\hline $\begin{array}{l}\text { Flow rate (-0.2 } \\
\text { mL.min-1) }\end{array}$ & 10.33 & 2.85 & 1.67 & 18558 \\
\hline Wavelength (+2 nm) & 8.88 & 3.21 & 1.4 & 29463 \\
\hline Wavelength (-2 nm) & 8.88 & 3.21 & 1.4 & 29524 \\
\hline Mean \pm SD. & $\begin{array}{c}9.04 \pm \\
0.68\end{array}$ & $3.22 \pm 0.25$ & $1.43 \pm 0.12$ & NA \\
\hline $\begin{array}{l}\text { Retention time } \\
\text { (tR), tailing factor } \\
\text { (tf), capacity factor } \\
\text { (k') and theoretical } \\
\text { plates (N) }\end{array}$ & & & & \\
\hline
\end{tabular}

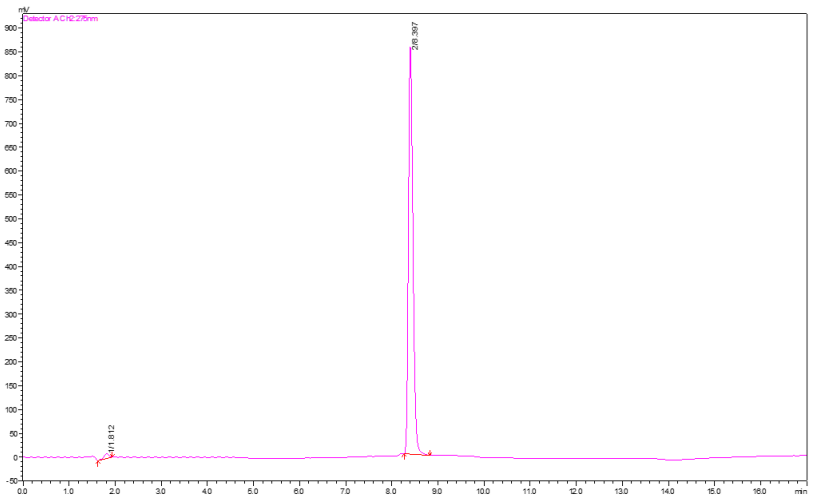

Figure 3: Robustness of Rifabutin Flow Rate $1.4 \mathrm{ml} / \mathrm{min}$.

Table 3: Robustness Study of Rifabutin.

Trifluoroacetic Acid, Acetonitrile (30:70 v/v)), flow rate by \pm 0.2 $\mathrm{ml} /$ minute, $\mathrm{CH}_{3} \mathrm{OH}( \pm 2 \%)$ and Wavelength $( \pm 2 \mathrm{~nm})$ keeping the other chromatographic parameters constant.

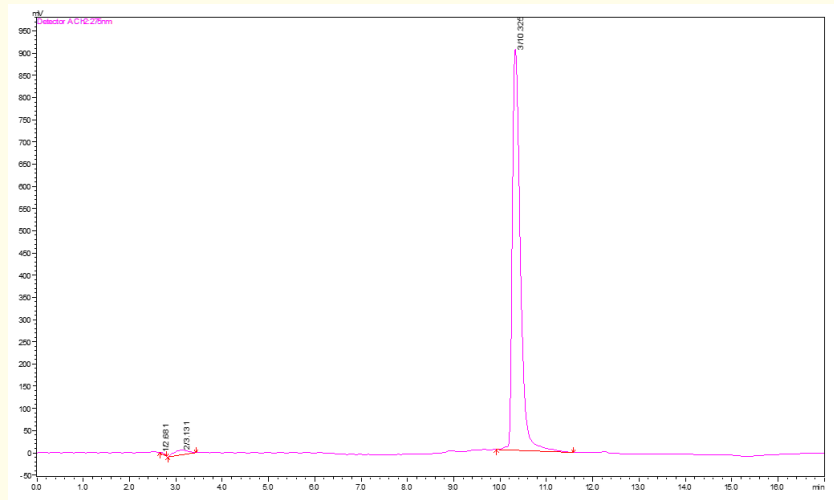

Figure 2: Robustness of Rifabutin Flow Rate 1ml/min.

Stability indicating studies of rifabutin or forced decomposition studies (Table 4)

Acid degradation studies

Acid decomposition study was performed by transferring $1 \mathrm{ml}$ of stock solution in to $10 \mathrm{ml}$ of volumetric flask. A volume of $2 \mathrm{ml}$ of $0.1 \mathrm{~N} \mathrm{HCl}$ solutions was added, mixed well and then kept for $12 \mathrm{~h}$ at $60^{\circ} \mathrm{C}$. Furthermore, the volume was adjusted with diluent to get the same concentration of drugs used for proposed method (Figure 6).

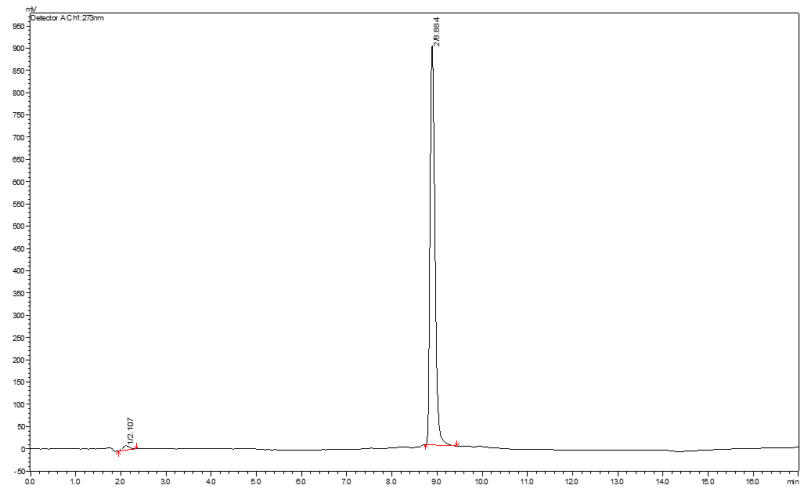

Figure 4: Robustness of Rifabutin Wavelength 273nm.

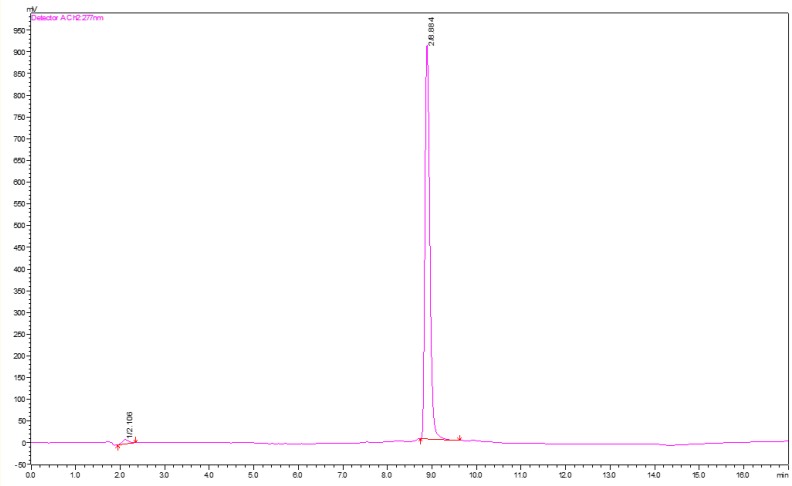

Figure 5: Robustness of Rifabutin Wavelength 277nm. 


\begin{tabular}{|l|c|c|}
\hline Conditions & $\begin{array}{c}\text { No. of degradants } \\
\text { (fragments) }\end{array}$ & \% degradation \\
\hline $\begin{array}{l}\text { Acid }(0.1 \mathrm{~N} / \mathrm{M} \mathrm{HCl})+60^{\circ} \mathrm{C} \\
+12 \mathrm{Hrs} .\end{array}$ & 2 degradant & $2.80 \%$ \\
\hline $\begin{array}{l}\text { Base }(0.1 \mathrm{~N} / \mathrm{M} \mathrm{NaOH})+ \\
60^{\circ} \mathrm{C}+12 \mathrm{Hrs} .\end{array}$ & 2 degradants & $5.10 \%$ \\
\hline Thermal $\left(60^{\circ} \mathrm{C}\right)+12 \mathrm{Hrs}$. & No degradation & None \\
\hline $\begin{array}{l}\text { Oxidation }(3-6 \% \mathrm{H} 2 \mathrm{O} 2)+ \\
\text { Room Temp. }\end{array}$ & No degradation & None \\
\hline Sunlight exposed +3 days & No degradation & Not Applicable \\
\hline
\end{tabular}

Table 4: Stability Indicating studies of Rifabutin.

\section{Base degradation studies}

Base decomposition study was performed by transferring $1 \mathrm{ml}$ of stock solution in to $10 \mathrm{ml}$ of volumetric flask. A volume of $2 \mathrm{ml}$ of $0.1 \mathrm{~N} \mathrm{NaOH}$ solutions was added, mixed well and then kept for $12 \mathrm{~h}$ at $60^{\circ} \mathrm{C}$. Furthermore, the volume was adjusted with diluent to get the same concentration of drugs used for proposed method.

\section{Thermal degradation studies}

Thermal degradation study was performed by transferring $1 \mathrm{ml}$ of stock solution in to $10 \mathrm{ml}$ of volumetric flask. The volumetric flask was stored at $60^{\circ} \mathrm{C}$ for $12 \mathrm{~h}$. Then, the volume was adjusted and the sample was analysed using the same proposed method.

\section{Oxidation decomposition studies}

Oxidation study was performed by transferring $1 \mathrm{ml}$ of stock solution in to $10 \mathrm{ml}$ of volumetric flask. A volume of $2 \mathrm{ml}$ of $3-6 \% \mathrm{H}_{2} \mathrm{O}_{2}$ solutions were added and mixed well and put at room temperature. After time period, the volume was adjusted with diluents to get the same concentration used for method development. The sample was then analysed using the same proposed method.

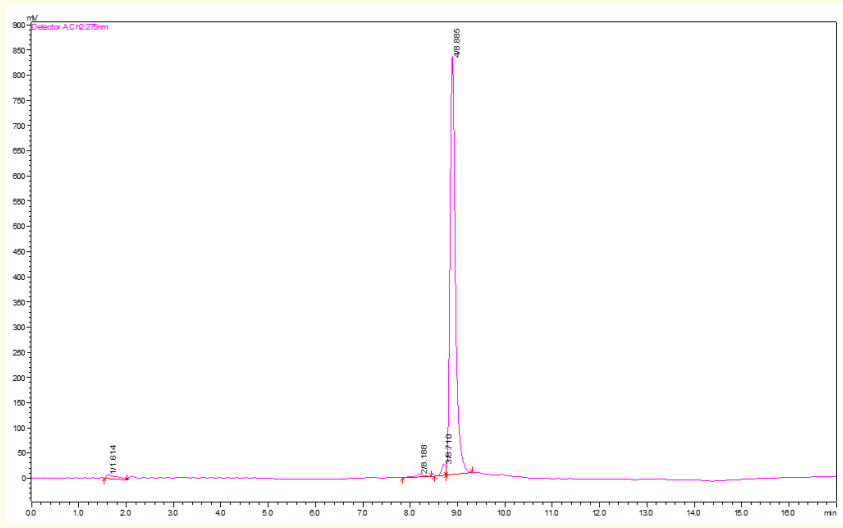

\section{Conclusion}

From all above results and discussion, it have been concluded that the proposed chromatographic (HPLC) analytical method for the Rifabutin is simple, specific, precise, accurate, HPLC analytical methods was developed and validated of Rifabutin as per ICH guidelines.

As per the ICH guidelines, the developed method has complied the precision studies (intraday and interday/intermediate), and robustness. Moreover, as per the ICH guidelines, the system suitability test performed for method development and validation of Rifabutin achieved all guidelines; including retention time $\left(t_{R}\right)$, tailing factor (tf), theoretical plates $(\mathrm{N})$ and capacity factor $\left(\mathrm{k}^{\prime}\right)$.

In addition, the stability indicating studies or force degradation studies were also performed for Rifabutin drug. As concluded, drug was seen stable in thermal, oxidation and acid induced hydrolysis.

Hence, it can be concluded that the developed methods are accurate, precise and selective and can be employed successfully for the estimation of Rifabutin in bulk and capsule dosage form.

\section{Acknowledgements}

The authors acknowledge Auriga Research Pvt. Ltd. Banglore, India for providing the gift sample of rifabutin for the purpose of this study.

\section{Conflict of Interest}

There is no conflict of interest.

\section{Bibliography}

1. Neesha Rockwood., et al. "Global access of rifabutin for the treatment of tuberculosis - why should we prioritize this?" Journal of the International AIDS Society 22.7 (2019): e25333.

2. Carlo Grassi and Vittoria Peona. "Use of Rifabutin in the Treatment of Pulmonary Tuberculosis". Clinical Infectious Diseases 22 (1996): S50-54.

3. Della Bruna C., et al. "LM 427, a new spiropiperidylrifamycin: in vitro and in vivo studies". Journal of Antibiotics (Tokyo) 36 (1983): 1502-1506.

4. Grassi C and Peona V. "Use of rifabutin in the treatment of pulmonary tuberculosis". Clinical Infectious Diseases 22 (1996): S50-S54.

Figure 6: Acid Degradation Studies Of Rifabutin 0.1M HCL. 
5. Narita M., et al. "Use of rifabutin with protease inhibitors for human immunodeficiency virus-infected patients with tuberculosis". Clinical Infectious Diseases 30.5 (2000): 779-783.

6. Heifets LB., et al. "Determination of MICs of conventional and experimental drugs in liquid medium by the radiometric method against Mycobacterium avium complex". Drugs Under Experimental and Clinical Research 13 (1987): 529-538.

7. Woodley CL and Kilburn 10. "In vitro susceptibility of Mycobacterium avium complex and Mycobacterium tuberculosis strains to a spiro-piperidyl rifamycin". American Review of Respiratory Disease Returns 126 (1982): 586-587.

8. Blaschke TF and Skinner MH. "The clinical pharmacokinetics of rifabutin”. Clinical Infectious Diseases 22 (1996): S15-21; discussion S-2.

9. Terrence F., et al. "The Clinical Pharmacokinetics of Rifabutin". Clinical Infectious Diseases 22 (1996): S15-S22.

10. DA Skoog., et al. "Analytical Chemistry". An Introduction, Saunders College Publications, 1-3.

11. DA Skoog., et al. "Principle of Instrumental Analysis". 5th ed., Eastern Press, Banglore (2004): 1-2, 678-688, 695-696.

12. GR Chatwal and SK Anand. "Instrumental Methods of Chemical Analysis". 5th ed., Himalaya Publishing House, Delhi (2004): 1.6-1.7, 2.156-2.158.

13. Frank Settle. "Handbook of Instrumental techniques for Analytical Chemistry”. NJ: Prentice Hall PTR: (1997): 17, 19, 56, 57.

14. Macherey-nagel. Macherey-nagel; Introduction into HPLC (2005).

15. RJ Hamilton and PA Sewell. "Introduction to HPLC". 2nd ed., Chapman and Hallondon (1982): 189.

16. Sethi PD. "HPTLC, Quantitative Analysis of Pharmaceutical Formulations". 1st ed, CBS Publishers and Distributors New Delhi (1997): 23.

17. RM Patel., et al. "Stability indicating HPLC method development-A review". International Research Journal of Pharmacy 2.5 (2011): 79-87.
18. Yogesh D Patil., et al. "RP-HPLC method for determination of Rifabutine in bulk dosage form". International Journal of Drug Development and Research 4.2 (2012).

19. Jaiprakas N Sangshetty., et al. "Stability indicating LC method for determination of Rifabutine in bulk drug and pharmaceutical dosage form". African Journal of Pharmacy and Pharmacology 5.3 (2011): 298-305.

20. https: / / database.ich.org/sites / default/files / Q2\%28R1\%29\%20Guideline.pdf

21. Fifield FW and Kealey D. "Principles and Practice of Analytical Chemistry". 5th ed. USA: Blackwell publishing 2 (2004): 5-7.

Volume 5 Issue 11 November 2021

(C) All rights are reserved by Seema B Kharwade., et al. 